\title{
O PAPEL DO JUDICIARIO NA PROTEÇÃO AOS REFUGIADOS
}

\author{
Thaís Guedes Alcoforado de Moraes $^{1}$
}

Resumo: A Lei brasileira de refúgio de 1997 é, até hoje, reconhecida como exemplo na região. Ano após ano, o Brasil vem se afirmando como um país de acolhida de refugiados. Contudo, ainda há muitos direitos violados e garantias desrespeitadas, o que traz à tona o debate sobre a atuação do Judiciário. Este trabalho visa a analisar criticamente os avanços e desafios enfrentados pela Justiça brasileira, com base na jurisprudência pátria, nos mais recentes acordos de cooperação institucional em prol do refúgio e na literatura especializada. Examina-se, também, o papel das instituições essenciais à Justiça neste contexto, especialmente a Defensoria Pública e o Ministério Público. Conclui-se que o Poder Judiciário desempenha o papel fundamental de efetivação dos direitos dos refugiados, ao garantir a observância dos compromissos internacionais assumidos pelo Brasil nesta seara.

Palavras-Chave: Refúgio. Judiciário. Proteção. Revisão judicial.Acesso à justiça.

Abstract: The Brazilian Refugee Law, which dates back to 1997, is still acclaimed as a best practice in the Latin American region today. Year after year, Brazil is reaffirming its role as a host country for refugees. However, abuses and violations of rights still happen, which brings about the debate on the role of the Judiciary in this subject. This paper aims to analyse the achievements and challenges faced by Brazilian Justice system, based upon the national jurisprudence, the most recent cooperation agreements and specialized literature. This work also

1 Advogada e Bacharela em Direito pela Universidade Federal de Pernambuco (UFPE). Assistente de Proteção do Alto Comissariado das Nações Unidas para Refugiados (ACNUR). 
examines the role of institutions which are considered essential to Justice, such as the Public Defender's Office and the Public Prosecutor's Office. It then arrives to the conclusion that the Judiciary plays a fundamental role in guaranteeing the rights of refugees and to enforce the respect to international treaties signed by Brazil regarding this issue.

Keywords: Asylum. Judiciary. Protection. Judicial review. Access to justice.

\section{INTRODUÇÃO}

As migrações de refugiados representam contemporaneamente uma questão de grande relevância para a política nacional e internacional, demandando respostas adequadas. De acordo com a definição clássica, estabelecida na Convenção de 1951 Relativa ao Estatuto dos Refugiados, refugiado é qualquer pessoa que tenha fundado temor de perseguição por motivos de raça, religião, nacionalidade, grupo social ou opiniões políticas; que se encontre fora do país de sua nacionalidade e que não possa ou, em virtude desse temor, não queira valer-se da proteção desse país.

Como afirmam Menezes e Reis (2013, p. 144), o ACNUR vem manifestando sua preocupação em relação ao desrespeito aos direitos humanos dos refugiados no mundo. A efetivação da integração local e a conquista da autossuficiência são necessárias para a concretização da proteção ao refugiado, e somente pode ser atingida em um contexto de observância aos direitos civis, sociais e econômicos. O ACNUR também destaca casos em que solicitantes e refugiados são detidos indevidamente ou devolvidos para zonas onde sua vida, liberdade e segurança estão ameaçadas. Frequentemente, é negado o acesso a tribunais e à assistência judiciária a esses indivíduos em centros de detenção, o que representa uma afronta direta ao art. 16 da Convenção.

O Brasil vem se afirmando como um país de acolhida de refugiados, desempenhando um papel de liderança em temas humanitários na região latino-americana. Atualmente, no Brasil, há 5.208 refugiados, o que ainda representa um número reduzido se comparado a outros países ${ }^{2}$. Contudo, o número de solicitações de refúgio vem crescendo

2 Até agosto de 2013, havia aproximadamente 55.000 refugiados no Equador, a maioria dos quais são colombianos. HUMAN RIGHTS WATCH, World Report 2014: Ecuador, 21 jan. 2014, Disponível em: <http://www.refworld.org/docid/52dfddf18.html >. Acesso em: 15 maio 2014. 
exponencialmente. Em 2010, foram apresentadas 566 solicitações, enquanto em 2013, este número atingiu a marca de 5.256 (REIS, 2014).

Internacionalmente, o Estado brasileiro tem demonstrado comprometimento com a temática do refúgio desde a criação do Alto Comissariado das Nações Unidas para Refugiados (ACNUR) em 1950. O Brasil é parte da Convenção das Nações Unidas de 1951 Relativa ao Estatuto dos Refugiados e do seu Protocolo de 1967, além de ter promulgado, em julho de 1997, a Lei de Refúgio (Lei $n^{\circ}$ 9.474/97), que instituiu o Comitê Nacional para os Refugiados (CONARE), um órgão interministerial presidido pelo Ministério da Justiça e vice-presidido pelo Ministério das Relações Exteriores, encarregado de tomar decisões quanto à elegibilidade de refugiados e à política nacional de refúgio.

A Lei de Refúgio estabeleceu que a determinação da condição de refugiado se daria através de um procedimento administrativo, cabendo ao CONARE a decisão dos casos em primeira instância, com possibilidade de recurso ao Ministro da Justiça no prazo de quinze dias da notificação da decisão (art. 31). Considerando que a competência para a decisão de reconhecimento do refúgio foi atribuída ao Executivo, cabe indagar qual seria o papel do Judiciário na proteção ao refugiado. É importante salientar que a proteção vai muito além do procedimento de determinação da condição de refugiado, abrangendo desde a chegada do estrangeiro ao país até a sua efetiva integração local na sociedade brasileira.

Para fins deste trabalho, o instituto do refúgio será caracterizado a partir de três referenciais: (I) o momento anterior ao reconhecimento da condição de refugiado, marcado pelas condições que levam o indivíduo a abandonar o país de origem e pelas circunstâncias de chegada ao país de acolhida; (II) o momento da determinação da condição de refugiado, que está relacionado ao deferimento ou não da solicitação de refúgio pelo órgão competente; (III) o momento posterior ao reconhecimento da condição de refugiado, isto é, a vida dessa pessoa no país de acolhida e a busca por uma solução duradoura efetiva para a sua situação.

Assim, este trabalho se propõe a explorar criticamente importantes desenvolvimentos na jurisprudência relativa ao refúgio, bem como algumas das oportunidades de provocação do Poder Judiciário para a garantia dos direitos dos refugiados, em cada um dos três momentos acima delineados.

\section{A CHEGADA AO PAÍS \\ DE REFÚGIO: A GARANTIA DE NÃO PENALIZAÇÃO DO REFUGIADO POR ENTRADA IRREGULAR}

O direito de solicitar refúgio está previsto no art. 14 da Declaração Uni- 
versal dos Direitos Humanos de 1948, o qual estabelece que: "Toda pessoa, vítima de perseguição, tem o direito de procurar e gozar de asilo em outros países". Disto decorre que o Estado tem o dever de tornar acessível o mecanismo do refúgio para os estrangeiros que cheguem ao seu território.

Dentre os direitos enunciados pela Convenção de 1951 e pela Lei no 9.474/97, enunciam direitos a serem observados em relação aos refugiados, que implicam deveres estatais correlatos. Dentre estes, ressalta-se o non-refoulement (não-devolução), isto é, a proibição de devolução do indivíduo para as fronteiras dos territórios em que a sua vida ou a sua liberdade seja ameaçada em virtude da sua raça, da sua religião, da sua nacionalidade, do grupo social a que pertence ou das suas opiniões políticas, conforme estabelece o art. 33 da Convenção.

Do princípio da non-refoulement, extrai-se a impossibilidade de rechaçar também os solicitantes de refúgio. É verdade que a Convenção de 1951 não aborda o tratamento aos solicitantes de forma expressa, mas apenas aos refugiados. Porém, o ato estatal de reconhecimento da condição de refugiado tem natureza jurídica declaratória, e não constitutiva (JUBILUT, 2011, p. 173; VELLOSO, 2012, p. 274).

Disto decorre que se um Estado falhar em garantir proteção aos solicitantes de refúgio - pessoas que potencialmente serão reconhecidas como refugiadas - estará arriscando descumprir as normas da Convenção de 1951 (WOLFE, 2012, p. 9). Em outras palavras, a aplicação dos postulados do Direito Internacional dos Refugiados a um indivíduo não depende de seu reconhecimento oficial como refugiado pelo Estado de acolhida. Assim, como bem salienta Jubilut (2011, p. 173), qualquer obstrução ao direito de solicitar refúgio seria uma violação do Direito Internacional e poderia ser objeto de análise pelo poder judiciário.

Considerando as circunstâncias gravosas em seu país de origem, a fuga do refugiado é muitas vezes urgente e diversos podem ser os obstáculos encontrados para sair de seu país. Em razão de regimes ditatoriais, conflitos ou políticas discriminatórias contra parcelas da população, a obtenção de documentos de viagem no país de origem do refugiado pode ser inviável. Esta situação pode levar o refugiado a buscar os meios mais ágeis de sair do seu país em busca de refúgio em um lugar seguro.

Tomando em conta esta realidade, $o$ art. 31 da Convenção determina o dever de não penalização dos refugiados por entrada irregular no território do país de acolhida. Este princípio também está disposto na Lei 9.474/97, em seu art. $8^{\circ}$, que dispõe: "O ingresso irregular no território nacional não constitui impedimento para o estrangeiro solicitar refúgio às autoridades competentes". $\mathrm{O}$ art. 10 da Lei de Refúgio estabelece 
que a solicitação de refúgio suspenderá qualquer procedimento administrativo ou criminal pela entrada irregular instaurado contra o solicitante.

Além disso, diversas diretrizes internacionais reiteram o fato de que solicitar refúgio não é um ato ilegal e, portanto, a detenção de solicitantes de refúgio deve permanecer como um último recurso, aplicado apenas excepcionalmente. Por outro lado, as decisões para deter ou estender a detenção devem estar sujeitas a garantias procedimentais mínimas, tais como:

I - Os solicitantes de refúgio devem ser informados, no momento da detenção, sobre as razões que a fundamentam, e sobre os seus direitos em conexão com a ordem de prisão, incluindo procedimentos de revisão, em um idioma que compreendam;

II - Os solicitantes de refúgio devem ser informados sobre o direito de aconselhamento legal;

III - Os solicitantes de refúgio devem ser apresentados imediatamente a uma autoridade judicial independente para que a decisão de detenção seja revisada (UNHCR, 2012, p. 27).

O Direito Internacional vem afirmando o dever dos Estados de instituírem garantias contra a arbitrariedade, sem as quais é provável que a detenção seja indevida. Estas garantias devem necessariamente incluir medidas alternativas à detenção. Caso estas alternativas não estejam disponíveis, os critérios da proporcionalidade, razoabilidade e necessidade não podem ser devidamente avaliados. Estes critérios devem ser aplicados a fim de garantir que a detenção seja aplicada como último recurso. Neste sentido, cabe aos Estados demonstrar que não havia, no caso concreto, uma medida menos coercitiva para atingir o mesmo objetivo (UNHCR, 2011, p. 25).

No mesmo sentido, deve-se considerar a Constituição Federal brasileira, ao determinar a vedação geral de prisão administrativa, em seu art. $5^{\circ}$, inciso LXI, nos seguintes termos: "ninguém será preso senão em flagrante delito ou por ordem escrita e fundamentada de autoridade judiciária competente".

Por outro lado, como o uso de documento falso é criminalizado no art. 304 do Código Penal brasileiro, refugiados são detidos com lamentável frequência, sem que se considere a o regime especial de direitos que lhes é aplicável.

Neste contexto, o Judiciário tem papel importante em assegurar a não penalização de refugiados por entrada irregular no território brasileiro, como se observa no seguinte julgado do Tribunal Regional Federal da 2a Região:

PROCESSUAL PENAL - PENAL - ACUSADOS PRESOS EM FLAGRANTE DELITO AO TENTAR EMBARCAR PARA ESTADOS UNIDOS DAAMÉRICA - NACIONALIDADE CUBANA - UTILIZAÇÃO DE PASSAPORTES FALSOS - DIREITO DE LIBERDADE EM CONFRONTO COM A TUTELA À FÉ PÚBLICA 
- JUÍZO DE PONDERAÇÃO - CIRCUNSTÂNCIA QUE DIANTE DO CASO CONCRETO LEVA A PRESENÇADA DIRIMENTE DE CULPABILIDADE - INEXIGIBILIDADE DE CONDUTA DIVERSA.

I-A prevalência dos direitos humanos justifica a conduta dos acusados, que se valendo documento falso tentam buscar a liberdade e seu pleno desenvolvimento em outro País, tudo em consonância com o respeito à dignidade da pessoa humana. II - Fato que não se podia exigir dos cidadãos Cubanos conduta em conformidade com o Direito, deixando caracterizada a inexigibilidade de conduta diversa como dirimente de culpabilidade a isentar de pena os Acusados. III - Apelação Criminal provida. (TRF2, ACR 4808, Processo 2005.51.01.515685-7, RJ, SEGUNDA TURMA ESPECIALIZADA, Relator MESSOD AZULAY NETO, DJ $02 / 06 / 2006$ )

Outro exemplo digno de destaque foi o recente caso de um cidadão afegão preso em Manaus por portar visto brasileiro falso ao se apresentar na Polícia Federal a fim de regularizar sua situação migratória. Em visitas da DPU e do ACNUR ao estabelecimento prisional, identificou-se que o estrangeiro desconhecia a possibilidade de solicitar refúgio no Brasil, embora manifestasse reiteradamente durante as entrevistas o seu temor da violência em seu país de origem e a sua intenção de buscar uma vida mais segura longe do Afeganistão (DPU, 2014).
Após intensa atuação conjunta do ACNUR e da DPU, foi revogada a prisão preventiva do solicitante. Em decisão de 22 de abril de 2014, a Justiça Federal do Amazonas reconheceu a desnecessidade e desproporcionalidade da prisão do afegão, sob o argumento de que "a condição jurídica de não-nacional do Brasil e a circunstância de o réu estrangeiro não possuir domicílio em nosso país não legitimam a adoção contra o acusado de qualquer tratamento arbitrário ou discriminatório" (DPU, 2014).

Por outro lado, já houve decisões no sentido contrário, isto é, julgados que priorizaram o bem jurídico da fé pública em detrimento da liberdade individual do solicitante de refúgio, como é o caso da decisão colacionada a seguir:

PENAL E PROCESSO PENAL. RÉU PRESO. USO DE DOCUMENTO FALSO, ART. 304 DO CÓDIGO PENAL. DEPORTAÇÃO. PEDIDO DE REFÚGIO. INTERESSE DA UNIÃO FEDERAL. CONFISSÃO ESPONTÂNEA. 1. Segundo o art. $6^{\circ}$ do Código Penal, o lugar do crime é aquele onde ocorreu a ação ou omissão, bem como o local em que se produziu ou deveria produzir-se o resultado.

2. Ocorrendo em território nacional o uso de documento falso, crime previsto no art. 304 do Código Penal, e, sendo crime de mera conduta, sua consumação se dá com o só fato de realizar a ação prevista no tipo legal, independentemente da produção de resultado. 3. O uso de passaportes falsos causa lesão à fé pública e à imagem do Brasil, pois se não fosse tal documento 
apreendido, e se tivessem conseguido os acusados entrar nos Estados Unidos, o descrédito das autoridades estrangeiras em relação aos documentos portados por cidadãos que imigram a partir deste país seria óbvio. Há, portanto, interesse da União no presente caso.

4. De acordo com o art. 12, I, da lei 9.474/97, o processamento e a apreciação de pedido de reconhecimento da condição de refugiado, com base na Convenção sobre o Estatuto dos Refugiados de 1951 e no Protocolo dos Refugiados de 1967, são de competência das autoridades administrativas, ou seja, do Comitê Nacional para Refugiados - CONARE, criado no âmbito do Ministério da Justiça.

5. Impossível a substituição da pena de prisão por restritiva de direito, ainda que inferior a quatro anos e não ser infração penal praticada com violência ou grave ameaça à pessoa, quando os réus não residem no Brasil, não falam o idioma nacional e nem podem permanecer legalmente no país.

6. Não se aplica a atenuante da confissão espontânea, art. 65, “d”, do Código Penal, se existem contradições nos depoimentos dados pelos apelantes perante o Juízo e a Polícia Federal.

7. Apelações não providas.(ACR 2004. 39.00.005319-5/PA, Rel. Desembargador Federal Tourinho Neto, Terceira Turma,DJ p.39 de 08/04/2005).

Decisões neste sentido desconsideram dispositivos legais expressos da Lei de Refúgio, especialmente os artigos $8^{\circ}$ e 10 , além de preterirem o princípio constitucional da dignidade da pessoa humana, o qual foi alçado à condição de fundamento da República Federativa do Brasil no art. $1^{\circ}$, inciso III da Constituição de 1988.

\section{O PROCEDIMENTO DE DETERMINAÇÃO DA CONDIÇÃO DE REFUGIADO: CONTROLE DE LEGALIDADE}

O procedimento de determinação da condição de refugiado foi estabelecido pela Lei 9.474/97, que estabeleceu um processo administrativo para a determinação da condição de refugiado. Portanto, aplica-se o princípio do devido processo legal, já que este incide tanto nos processos judiciais quanto nos administrativos. É o que determina a Constituição Federal, ao dispor, por exemplo, em seu art. $5^{\circ}$, inciso LV, que: "aos litigantes, em processo judicial ou administrativo, e aos acusados em geral são assegurados o contraditório, com os meios e recursos a ele inerentes."

Quanto ao processo administrativo, o princípio do devido processo legal constitucionalmente assegurado significa, em primeiro lugar, o dever da Administração Pública de atuar material e formalmente segundo o que o Direito determina. Assim, o devido processo legal administrativo concerne tanto à forma quanto ao conteúdo das decisões administrativas, e por ele se garante a certeza tanto do dever público quanto do direito do particular na relação administrativa (MOREIRA, 2010, p. 291). 
Do fato de que o devido processo legal deve ser tomado em conta tanto formal quanto materialmente, decorre que não basta a observância aos trâmites processualísticos, mas também é necessário que os direitos fundamentais do administrado sejam respeitados.

Ademais, considerando que o reconhecimento da condição de refugiado é um ato declaratório, como determina expressamente $\mathrm{o}$ art. 26 da Lei 9.474/97, tanto a decisão do CONARE quanto a do Ministro da Justiça não escapam do controle judicial. Seria, pois, a concessão do refúgio ato administrativo vinculado (VELLOSO, 2012, p. 278). Neste sentido, em argumento contra a discricionariedade estatal no reconhecimento da condição de refugiado, defende Pietro Alarcón (2013, p. 113):

Uma interpretação sistemática, que leve em conta a dignidade humana, a defesa do direito à vida e às liberdades proclamadas na Declaração Universal e em Documentos como a Convenção Americana de Direitos Humanos, o Estatuto dos Refugiados, a Declaração de Cartagena e a Declaração ou Plano de Ação do México e, ainda, o leque de direitos considerados fundamentais nos textos constitucionais, impede ao Estado negar o direito ao refúgio quando a pessoa se encontre em circunstâncias que levem a risco esses direitos. O refúgio, assim, funciona como um meio para defender esses outros direitos.

O princípio da universalidade de jurisdição, previsto no art. $5^{\circ}, \mathrm{XXXV}$, da Constituição Federal, permite a revisão das decisões administrativas pelo Poder Judiciário, quando houver lesão ou ameaça a direito.

Apesar disso, já houve decisões que defendiam a discricionariedade do Poder Público na concessão do status de refugiado, bem como a impossibilidade de intervenção do Judiciário para revisar a legalidade da decisão administrativa sobre refúgio. É o que exemplificam as seguintes decisões:

AGRAVO DE INSTRUMENTO. ESTRANGEIRO. DECLARAÇÃO DA CONDIČ̃̃O DE REFUGIADO. GUERRA NO PAÍS DE ORIGEM. ALTO GRAU DEDISCRICIONARIEDADE DA ADMINISTRAÇÃO.

1. O controle de estrangeiros no território brasileiro quanto à entrada, permanência e saída compulsória é matéria cometida à Administração com elevado grau de discricionariedade.

2. Os compromissos brasileiros com a proteção dos direitos humanos não afastam a discricionariedade no exame dos casos individuais de pedido de proteção. Tal exame de conveniência deflui da responsabilidade diplomática cometida ao Chefe do Executivo, em exercício de soberania estatal perante a sociedade internacional, e revela circunstâncias delicadas de responsabilidades e ônus nesse campo.

3. Não reconhecida a condição de refugiado após conclusão de regular processo administrativo, não cabe ao Poder Judiciário intervir para modificar a decisão da administração. É pertinente a ordem de saída do Brasil sob pena de deportação, observado que implementada uma 
ou outra situação não há restrição para que se postule imigração por outras formas disponíveis. (TRF4, Agravo de Instrumento 2007.04.00.0376365, Relator Des. Marcelo de Nardi, DE 05/03/2008).

DIREITO INTERNACIONAL PÚBLICO.AÇÃO ORDINÁRIA. PEDIDO DE CONCESSÃO DE REFÚGIO. PERMANÊNCIA PROVISÓRIA. INDEFERIMENTO. O reconhecimento da condição de refugiado é ato decorrente do Poder Soberano do Estado solicitante e, portanto, ato eminentemente político, excluído da apreciação do Poder Judiciário no tocante ao seu conteúdo material. Ato revestido de legalidade formal. (TRF4, Agravo de Instrumento 2008.04.00.0045298, Relator Des.

Valdemar Capeletti, DE 16/02/2009).

Estas decisões incorrem em grave equívoco, pois, ao afirmarem que o reconhecimento da condição de refugiado é "ato eminentemente político, excluído da apreciação do Poder Judiciário no tocante ao seu conteúdo material", desconsideram o caráter apolítico e humanitário do refúgio. Além disso, deixam transparecer confusão conceitual entre dois institutos distintos, quais sejam, o refúgio e o asilo político. Como bem salienta Mazuolli (2010, p. 689):

Enquanto o instituto do asilo é regulado por tratados multilaterais bastante específicos de âmbito regional, que nada mais fizeram do que expressar o costume até então aplicado no continente americano, o refúgio tem suas normas elaboradas por uma organização (com alcance global) de fundamental impor- tância vinculada às Nações Unidas: o Alto Comissariado das Nações Unidas para Refugiados (ACNUR). No que tange ao Direito brasileiro, igualmente, os institutos recebem tratamento jurídico totalmente diferenciado: enquanto do primeiro cuida o Estatuto do Estrangeiro e seu Regulamento, do segundo versa a bem mais recente Lei n. 9474, de 22 de julho de 1997.

Desta forma, em atenção à argumentação tecida acima, a interpretação mais acertada seria a exposta no seguinte julgado:

ADMINISTRATIVO. ESTRANGEIRO. CONDIÇÃO DE REFUGIADO. LEI 9.474/97, ART. $1^{\circ}$. CF/88, ART. $5^{\circ}, \mathrm{XXXV.}$

I - A Carta Magna estabelece que a lei não excluirá da apreciação do Poder Judiciário lesão ou ameaça a direito" (art. $5^{\circ}$, inciso XXXV), sendo função primordial deste poder zelar pela fiel observância das leis.

II - Embora não se reconheça ao judiciário a competência para incursão no mérito do ato administrativo, no caso sob apreciação não se trata de adentrar o mérito do ato, para examinar critérios de oportunidade e conveniência, mas do exame de legalidade da decisão, que, apreciando o caso concreto e interpretando a lei a ele aplicável, entendeu não se enquadrar a hipótese nos seus dispositivos.

III - O art. $1^{\circ}$ da Lei n. 9.474/97 reconhece como refugiado todo indivíduo que, "devido a fundados temores de perseguição por motivos de raça, religião, nacionalidade, grupo social ou opiniões políticas encontre-se fora de seu país de nacionalidade e não possa 
ou não queira acolher-se à proteção de tal país", hipótese configurada nos autos. IV - Antecipação dos efeitos da tutela ab initio litis, ainda que a sentença decrete a improcedência da ação, persiste na hipótese de recebimento do apelo em seu duplo efeito.

$\mathrm{V}$ - Sentença reformada.

VI - Apelação do autor provida. Condição de refugiado reconhecida. (AC 0001186-93.2006.4.01.4200/RR, Rel.

Desembargador Federal Jirair Aram Meguerian, Sexta Turma,e-DJF1 p. 93 de 28/02/2011).

Uma orientação neste sentido não representa uma incursão indevida do Judiciário na esfera do Executivo, uma tendência à judicialização do refúgio ou ao ativismo judicial, com os quais alguns teóricos se preocupam (BARROSO, 2012, p. 25). Em vez disso, decisões neste viés materializam o papel primordial do Judiciário em processos administrativos, além de garantir o cumprimento dos compromissos de Direito Internacional dos Refugiados e Direitos Humanos assumidos pelo Estado brasileiro.

\section{A INTEGRAÇÃO AO PAÍS DE REFÚGIO: O ACESSO A POLÍTICAS PÚBLICAS E ASSISTÊNCIA SOCIAL}

Uma vez reconhecidos pelo Estado brasileiro como refugiados, há três soluções duradouras possíveis para estes indivíduos: em primeiro lugar, a inte- gração local, em que o refugiado busca se integrar à comunidade de acolhida, por meio principalmente da obtenção de emprego, estudos, constituição de família etc.; em segundo lugar, a repatriação voluntária, em que o refugiado retornará ao seu país originário, quando cessem as condições que deram causa ao refúgio; e por fim, o reassentamento, caso em que o refugiado já foi reconhecido por um primeiro país de refúgio, porém é transferido a um segundo país (UNHCR, 2003, p. 5-6).

Dentre as soluções duradouras, o Brasil prioriza a integração local (MILESI, 2009, p. 318). De acordo com Crisp (2004, p. 1), a integração local é um processo multidimensional, que apresenta aspectos legais, pelos quais o refugiado conquista direitos no país receptor; econômicos, pelos quais participam da economia local; e sociais, através dos quais tais imigrantes passam a conviver e fazer parte da sociedade do novo país.

$\mathrm{O}$ art. $5^{\circ}$, caput, da Constituição assegura tratamento igualitário aos brasileiros e estrangeiros residentes no país. A Lei 9.474/97, por sua vez, expressou o compromisso do Brasil com a causa humanitária do refúgio, chamando o Estado a efetivar estes direitos, quando sinalizou para a implementação de políticas públicas para a integração dos refugiados.

Como bem salienta Menezes (2009, p. 94), embora o Brasil possua uma abrangente legislação e haja incorpo- 
rado todos os instrumentos regionais e internacionais de proteção aos refugiados, ainda há grave insuficiência nas condições econômicas e no alcance das políticas públicas concretas de médio e longo prazo, com vistas à integração dos refugiados na sociedade brasileira. Diz-se, pois, que não há propriamente uma política para refugiados, já que os direitos deste grupo populacional são relegados ao segundo plano no processo de integração à sociedade brasileira.

Neste contexto, os refugiados têm dificuldade em acessar diversas políticas públicas pela via administrativa, devido a entraves legais e burocráticos diversos, o que por vezes torna necessária uma demanda judicial. Como bem salienta Milesi (2009, p. 323):

Mesmo que haja políticas abertas a todos - nacionais e refugiados - são necessários mecanismos específicos para que estes últimos tenham acesso a elas. Por exemplo, experiência prévia para o acesso ao mercado de trabalho, histórico escolar e classificação qualitativa para o acesso à universidade, tempo de residência na localidade para o acesso à moradia, são condições que podem inviabilizar ou afastar definitivamente os refugiados, se não forem adotados critérios que levem em conta suas condições específicas em relação aos nacionais.

Neste aspecto, o Judiciário tem exercido importante papel ao balizar o acesso dos refugiados a políticas públicas de integração. Um exemplo emblemático é a discussão no Supremo Tribunal Federal sobre a possibilidade de conceder o Benefício de Prestação Continuada, previsto na Lei Orgânica de Assistência Social, a estrangeiros residentes no país, inclusive refugiados. A questão teve sua repercussão geral reconhecida pelo STF em 2009, no Recurso Extraordinário 587.970-4/SP, e resta pendente de decisão.

A seguir, explorar-se-á sucintamente o debate jurídico travado sobre a questão, uma vez que ele elucida a questão fundamental sobre o papel do Judiciário no acesso do refugiado a políticas públicas.

\section{O CASO DO BENEFÍCIO DE PRESTAÇÃO CONTINUADA (BPC/LOAS)}

A Constituição Brasileira de 1988 inovou ao conferir à assistência social, em seus art. 203 e 204, o caráter de universalidade de acesso e cobertura, além de estabelecer a responsabilidade estatal no financiamento das políticas de assistência. Como bem analisa José Afonso da Silva (1995, p. 300):

O direito à assistência social constitui a face universalizante da seguridade social, porque 'será prestada a quem dela necessitar, independentemente de contribuição' (art. 203). Nela é que, também, assenta outra característica da seguridade social: a solidariedade financeira, já que os recursos procedem do orçamento geral da seguridade social e não de contribuições específicas de even- 
tuais destinatários (art. 204), até porque estes são impersonalizáveis a priori, porquanto se constituem daqueles que não dispõem de meios de sobrevivência.

No art. 203, inciso V, a Constituição prevê o Benefício de Prestação Continuada, que seria devido às pessoas portadoras de deficiência e aos idosos que comprovem não possuir meios de prover à própria manutenção ou de tê-la provida por sua família. Este benefício foi regulado no art. 20 da Lei no 8.742/1993, a Lei Orgânica de Assistência Social (LOAS), posteriormente alterada pela Lei $\mathrm{n}^{\circ}$ 12.435/2011, que dispõe:

Art. 20. O benefício de prestação continuada é a garantia de um salário-mínimo mensal à pessoa com deficiência e ao idoso com 65 (sessenta e cinco) anos ou mais que comprovem não possuir meios de prover a própria manutenção nem de tê-la provida por sua família.

Em seu art. $1^{\circ}$, a LOAS refere-se à assistência social como "direito do cidadão". A terminologia empregada neste dispositivo trouxe dúvidas a respeito do alcance dos programas de assistência, pois não restou claro se "cidadão" corresponderia a "nacional brasileiro". A redação atual do Decreto $\mathrm{n}^{0} 7.617 / 2011$, que regulamenta o $\mathrm{BPC} / \mathrm{LOAS}$ restringiu a abrangência do benefício ao "brasileiro, naturalizado ou nato, que comprove domicílio e residência no Brasil".
Contudo, esta restrição está eivada de inconstitucionalidade, uma vez que:

I - $\mathrm{O}$ art. $5^{\circ}$, caput da $\mathrm{CF} / 88$, bem como o art. 95 da Lei ${ }^{\circ} 6.815 / 1980$ (Estatuto do Estrangeiro) determinam a igualdade de direitos entre brasileiros e estrangeiros residentes no país;

II - O BPC/LOAS é um dos objetivos constitucionais da assistência social, conforme o art. 203, inciso V da $\mathrm{CF} / 88$, e não consta da Constituição restrição alguma a estrangeiros;

III - A restrição a direito fundamental prevista em Decreto não pode prevalecer em relação à disposição constitucional e legal.

Saliente-se ainda que, no caso específico dos refugiados, a Convenção de 1951 e a Lei de Refúgio demandam do Estado a adoção de medidas efetivas de proteção. Assim, embora a maior parte dos refugiados que cheguem ao Brasil integrem-se localmente, contribuindo para o mercado de trabalho e para o crescimento do país, há também refugiados que correspondem aos requisitos legais - isto é, são idosos e/ ou portadores de deficiência incapazes de prover o próprio sustento. Nestes casos, resta evidente que a restrição ao benefício previsto na LOAS é uma afronta ao princípio da dignidade humana e da prevalência dos direitos humanos. Diante do exposto, conclui-se que a restrição do BPC/LOAS a nacional brasileiro é inconstitucional tanto material quanto formalmente. 


\section{A ATUAÇÃO DE INSTITUIÇÕES ESSENCIAIS À JUSTIÇA NA PROTEÇÃO AO REFUGIADO}

Considerando que o Judiciário apenas atua quando provocado, é fundamental fazer menção neste artigo sobre a atuação das instituições essenciais à Justiça, especialmente a Defensoria Pública e o Ministério Público, que também desempenham importante papel na proteção aos refugiados. Neste tópico, analisamos sucintamente os últimos desenvolvimentos neste sentido, bem como oportunidades de aprofundamento da atuação destes órgãos na defesa e promoção dos direitos dos refugiados.

Em primeiro lugar, a Defensoria Pública é importante aliada para a concreção da proteção efetiva aos refugiados, uma vez que a efetivação dos direitos humanos e assistência aos necessitados estão entre seus objetivos institucionais. A Lei Complementar $n^{\circ} 132$, de 7 de outubro de 2009 incrementou as funções institucionais da Defensoria Pública, tornando explícita sua vocação para promover os direitos humanos.

A Lei discorre sobre a proteção dada aos refugiados pelo Direito Internacional dos Direitos Humanos, bem como seus reflexos no arcabouço jurídico brasileiro; faz considerações sobre o devido processo legal para a análise da condição de refugiado dos estrangeiros que aportam no país; constata a necessidade de assistência pela Defensoria Pública desde o início do procedimento perante a Polícia Federal, para tanto devendo, obrigatoriamente, ser comunicada de sua abertura (LIMA DE SÁ, 2010, p. 37).

Quanto ao último ponto, a DPU vem inclusive demandando o CONARE judicialmente a intimar pessoalmente o Defensor Público das decisões das solicitações de refúgio. Argui-se que a intimação pessoal é uma prerrogativa da Defensoria que, se aplicada ao procedimento de elegibilidade, elevaria o parâmetro de devido processo legal, ampla defesa e contraditório na determinação da condição de refugiado. O solicitante de refúgio, por sua vez, estaria melhor assistido juridicamente - o que se torna crítico no momento do recurso ao Ministro da Justiça, nos casos em que o pedido de refúgio é indeferido. É o caso do seguinte julgado:

ADMINISTRATIVO. INTIMAÇÃO PESSOAL DE MEMBRO DA DEFENSORIA PÚBLICA DA UNIÃO NO ÂMBITO DE PROCESSO ADMINISTRATIVO DE REFÚGIO. DEVOLUÇÃO DE PRAZO PARA APRESENTAÇÃO DE RECURSO. REMESSA NECESSÁRIA E APELAÇÃO IMPROVIDAS.

1. Cuida-se de remessa necessária e recurso de apelação interposto contra sentença que, acolhendo a pretensão deduzida em demanda cognitiva proposta pela Defensoria Pública da União e estrangeiro, devolveu prazo a nacional de Angola para interpor recurso no âmbito 
de processo administrativo instaurado perante o CONARE, órgão vinculado ao Ministério da Justiça provocado para apreciar pedido de refúgio.

2. Em que pese a ciência pessoal do estrangeiro demandante acerca da decisão que indeferiu o pedido administrativo de refúgio (fls. 32), comprovado está nos autos que o mesmo formulou requerimento de refúgio junto ao CONARE por intermédio de Defensor Público da União.

3. A prerrogativa de intimação pessoal dos membros da Defensoria Pública está prevista na Lei Complementar ${ }^{\circ}$ 80/94, norma que assegura, além da entrega dos autos com vista, sua incidência nos processos judiciais e administrativos.

4. Apelação e remessa necessária improvidas. (TRF2, AC 201151010139195AC - APELAÇÃO CIVEL - 592747 - Relatora Des. CARMEN SILVIA LIMA DE ARRUDA, DE 25/11/2013).

Dada a sua importante atuação em prol dos refugiados judicial e extrajudicialmente, a Defensoria Pública da União passou a integrar o CONARE em 2012 como membro consultivo com voz, sem voto, a partir de Acordo de Cooperação Técnica entre a DPU, a Secretaria Nacional de Justiça (SNJ) e o CONARE (DPU, 2013). Em discurso na $74^{\mathrm{a}}$ sessão da Comissão de Constituição e Justiça do Senado Federal, o Defensor Público Geral, Haman Tabosa, discorreu sobre estes recentes desenvolvimentos:

Tomando essa frente da área de estrangeiros, obtivemos junto ao Secretário Paulo Abrão da Secretaria Nacional de
Justiça do Ministério da Justiça, um acordo de cooperação e temos assento e voz no Conare - Comitê Nacional para os Refugiados. A Defensoria Pública ajuda a analisar os casos de pedidos de refúgio também para evitar que aquele que tenha indeferido seu pedido de refúgio nos procure para que ajuizemos uma ação na Justiça visando ao reconhecimento dessa condição de refúgio. Também é uma forma não apenas de dar ampla defesa a essas pessoas, mas também de evitar novamente a judicialização. (SENADO FEDERAL, 2013).

Assim, percebe-se que, nos últimos anos, a DPU vem intensificando em várias frentes sua cooperação com instituições que lidam com refúgio, especialmente o ACNUR, o CONARE e as organizações da sociedade civil.

O Ministério Público, por outro lado, vem atuando de forma mais tímida, porém identificam-se muitas oportunidades de cooperação na área de proteção aos refugiados. Afinal, o Ministério Público, além de órgão acusador, é também fiscal da lei, e pode, portanto, desempenhar importante papel na fiscalização da aplicação da Lei de Refúgio.

Tornam-se, pois, necessárias mais ações de sensibilização junto ao Ministério Público, a fim de que a instituição ofereça pareceres pautados nos princípios de Direito Internacional dos Refugiados. Outra área de atuação importante seria a atuação proativa do MP na acusação em casos de violação dos direitos dos refugiados como, por exemplo, em casos de exploração trabalhista 
ou de negação indevida do acesso a políticas públicas.

Ainda, o MP pode apoiar financeiramente projetos em prol desta população. Uma excelente iniciativa recente neste sentido partiu do Ministério Público do Trabalho no Rio de Janeiro, que reverterá verbas das multas trabalhistas recolhidas para a construção de um abrigo para refugiados.

Em abril de 2014, foi firmado Protocolo de Intenções entre as partes, por meio do qual as receitas provenientes de termos de ajustamento de conduta e de acordos e condenações judiciais poderão ser revertidas para projetos assistenciais desenvolvidos pela instituição. O protocolo vigorará por dois anos, mas poderá ser prorrogado. Ficou acordado que, nesse período, os recursos obtidos em ações civis públicas perante o MPT serão revertidos para implementar projetos da Cáritas-RJ,especialmente na área de relações de trabalho e emprego, com ênfase no treinamento e capacitação de mão-de-obra. Os projetos serão desenvolvidos com o apoio do ACNUR (ONU BRASIL, 2014).

Diante do exposto, conclui-se que os últimos anos têm testemunhado avanços importantes no tocante à proteção dos refugiados a partir de ações das instituições essenciais à Justiça. Ainda assim, há diversos caminhos ainda por serem trilhados no sentido de um uso cada vez mais eficiente e estratégico do sistema judiciário.

\section{CONIDERAÇÕES FINAIS}

Este trabalho tentou analisar de forma crítica o papel que o Judiciário vem assumindo na proteção ao refugiado no Brasil nos últimos anos, sopesando os avanços e os desafios que se apresentam nesta seara.

Em breve síntese do papel do Judiciário no procedimento de refúgio, temse que: enquanto ao Legislativo cabe a incorporação dos compromissos internacionais ao ordenamento jurídico nacional, através da elaboração de leis, ao Executivo corresponde instrumentalizar estas normas, possibilitando a sua efetivação. Por fim, o Judiciário atua primordialmente no controle de legalidade, a fim de garantir que os atos da Administração estejam pautados na Lei e nos compromissos internacionais assumidos pelo Estado brasileiro.

Contudo, o papel do Judiciário não se restringe ao momento da determinação da condição de refugiado. O mecanismo do refúgio é complexo e envolve diversos aspectos, que podem ser resumidos em três fases: a primeira seria o momento de chegada ao Brasil, a segunda seria a fase de determinação do status de refugiado e a terceira seria a fase em que, uma vez deferida a solicitação de refúgio, o indivíduo passa a integrar-se à sociedade de acolhida de maneira mais ou menos definitiva.

Claro está que esta divisão é demasiado simples para elucidar a complexi- 
dade do refúgio, uma vez que não considera, por exemplo, a hipótese de que o pedido seja indeferido. Além disso, é notório que o processo de integração local, longe de estar limitado a uma "última fase", inicia-se muito antes do deferimento da solicitação, isto é, desde a chegada do estrangeiro ao país de aco1hida. Contudo, a categorização nestas três fases é útil para explorar de forma mais sistemática diferentes aspectos da atuação do Judiciário neste processo.

Em linhas gerais, na primeira fase, o Judiciário tem papel importante na garantia de não devolução e não penalização pela entrada irregular. Na segunda fase, tem-se o controle de legalidade, tanto do aspecto formal quanto do material, do procedimento administrativo de determinação da condição de refugiado. Por fim, uma vez deferida a solicitação, o Judiciário continua exercendo papel

\section{REFERÊNCIAS}

BARROSO, Luís Roberto. Judicialização, Ativismo Judicial e Legitimidade Democrática. Cadernos Synthesis. Rio de Janeiro, v. 5, n. 1, p. 23-32.

BRASIL. Defensoria Pública da União. Afegão solicitante de refúgio é solto após dois meses preso em Manaus. 28 abr. 2014. Disponível em: $<$ http://www.dpu.gov.br/index. php?option=com_content\&vie$\mathrm{w}=$ article \&id=21236:afegao-so- decisivo, pois pode atuar pela garantia de acesso dos refugiados às políticas públicas e assistência social, impulsionando o processo de integração local destas pessoas.

Tampouco se pode olvidar da atuação das instituições essenciais à Justiça, mormente o Ministério Público e a Defensoria Pública, que tem cooperado de formas diversas com a causa do refúgio e que ainda apresentam enorme potencial de atuação estratégica neste sentido.

Em suma, o Poder Judiciário desempenha o papel fundamental de efetivação dos direitos dos refugiados, solicitantes de refúgio e apátridas. Este papel é subsidiário e excepcional, mas muito relevante, pois garante a observância dos compromissos internacionais de direitos humanos e de Direito Internacional dos Refugiados assumidos pelo Brasil.

licitante-de-refugio-e-solto-aposdois-meses-preso-em-manaus\&catid $=79 \&$ Itemid $=220>$. Acesso em: 10 maio 2014.

BRASIL. Defensoria Pública da União. Manaus faz entrevistas de elegibilidade de solicitantes de refúgio. 02 out. 2013. Disponível em: $<$ http://www.dpu.gov.br/internacional/index.php/en/component/ content/article/42-noticias/389- 
02102013-manaus-faz-entrevistasde-elegibilidade-de-solicitantesde-refugio $>$. Acesso em: 09 maio 2014.

BRASIL. Senado Federal. Comissão de Constituição, Justiça e Cidadania - 74a Reunião. 03 dez. 2013. Disponível em: $<$ http://www.senado. gov.br/atividade/comissoes/sessao/ escriba/notas.asp?cr=2197>. Acesso em: 09 maio 2014.

CRISP, Jeff. The local integration and local settlement of refugees: a conceptual and historical analysis. New Issues in Refugee Research. Working Paper n. 102. Genebra: UNHCR, 2004.

REIS, Thiago. Portal de Notícias G1. Brasil tem hoje 5,2 mil refugiados de 79 nacionalidades. G1 São Paulo, 24 abr. 2014. Disponível em: <http://g1.globo.com/mundo/ noticia/2014/04/brasil-tem-hoje52-mil-refugiados-de-79-nacionalidades-diferentes.html $>$. Acesso em: 15 maio 2014.

JUBILUT, Liliana Lyra. A Judicialização do Refúgio. In: RAMOS, André de Carvalho; RODRIGUES, Gilberto; ALMEIDA, Guilherme Assis de. 60 Anos de ACNUR: Perspectivas de Futuro. São Paulo: CL-A Cultural, 2011.

LIMA DE SÁ, Waltenberg. Uma nova função da Defensoria Pública perante o Direito Internacional dos Direitos Humanos. Revista da De- fensoria Pública da União, Brasília, n. 4, p. 81-96, 2010.

MAZUOLLI, Valério de Oliveira. Curso de Direito Internacional Público. 4. ed. São Paulo: Revista dos Tribunais, 2010.

MENEZES, Thaís Silva; REIS, Rossana Rocha. Direitos humanos e refúgio: uma análise sobre o momento pósdeterminação do status de refugiado. Revista Brasileira de Política Internacional, Rio de Janeiro, 2013, v. 56, n. 1, p. 144-162.

MENEZES, Wagner. Estudos de Direito Internacional. Anais do 7.o Congresso Brasileiro de Direito Internacional. v. XVIII. São Paulo: 2009. p. 94.

MILESI, Rosita. O refúgio no contexto das migrações: a integração dos refugiados e refugiadas como solução duradoura. Revista Interdisciplinar de Mobilidade Humana, Brasília, ano XVII, n. 33, p. 317-323, 2009. MOREIRA, Egon Bockmann. Processo administrativo: princípios constitucionais e a Lei 9.784/1999. São Paulo: Malheiros, 2010.

MOREIRA, Júlia Bertino. Política em relação aos refugiados no Brasil (1947 - 2010). Tese (Doutorado). Instituto de Filosofia e Ciências Humanas. Universidade Estadual de Campinas. Campinas, 2012.

ONU BRASIL. ACNUR e MPT assinam convênio para reverter verbas para projetos de capacitação de 
refugiados no Rio. 30 abr. 2014. UNHCR. Guidelines on the Applicable Disponível em: $<$ http://www.onu. Criteria and Standards relating to org.br/acnur-e-mpt-assinam-convenio-para-reverter-verbas-para-projetos-de-capacitacao-de-refugiadosno-rio/>. Acesso em: 09 maio 2014. SILVA, José Afonso da. Curso de Direito Constitucional Positivo. 10. ed. São Paulo: Malheiros, 1995.

UNHCR. Back to Basics: The Right to Liberty and Security of Person and 'Alternatives to Detention' of Refugees, Asylum-Seekers, Stateless Persons and Other Migrants. Legal and Protection Policy Research Series. PPLA/2011/01. Rev. 1, abr. 2011. Disponível em: <http://www. refworld.org/docid/4dc935fd2. html>. Acesso em: 13 maio 2014.

UNHCR. Framework for Durable Solutions for Refugees and Persons of Concern. maio 2003. Disponível em: $<$ http://www.refworld.org/docid/4124b6a04.html>. Acesso em: 15 maio 2014. the Detention of Asylum-Seekers and Alternatives to Detention, 2012. Disponível em: $<\mathrm{http}: / / w w w$. refworld.org/docid/503489533b8. html >. Acesso em: 13 maio 2014. VELLOSO, Carlos Mário da Silva. Natureza jurídica do ato concessivo do status de refugiado e seu controle pelo Poder Judiciário. Parecer elaborado a pedido da Itália. 2012. Disponível em: <http://bibliotecadigital.fgv.br/ojs/index.php/ rda/article/download/4146/2929>. Acesso em: 15 maio 2014.

WOLFE, Tara. The Detention of Asylum Seekers in Europe. 2011. Disponível em: $<$ http://www.guildhallchambers.co.uk/files/Tara_Wolfe_The Detention_of_Asylum-Seekers_in Europe_Dissertation.pdf $>$. Acesso em: 15 maio 2014. 